\section{Impression cytology of the conjunctival epithelium in patients with chronic renal failure}

\author{
Dilek Dursun, Beyhan Demirhan, Sibel Oto, Pinar Aydin
}

Conclusion-The ocular surfaces of CRF patients differ significantly from those of normal individuals, and it can be detected using impression cytology. These data suggest that the severity of conjunctival changes are not related to the presence or extent of calcium deposition. (Br f Ophthalmol 2000;84:1225-1227)

The visual system may be adversely affected by chronic renal failure (CRF) as a result of uraemia, metabolic imbalances, hypertension, or the haemodialysis treatment. ${ }^{12}$

Anterior segment findings typically consist of amorphous, white, crystalline, and subepithelial calcific deposits confined to the exposed limbal area. Occasionally, the lesions are located at the limbus in a pattern similar to the type II limbal girdle of Vogt and in advanced stages they manifest as band keratopathy. ${ }^{1-6}$ Different aetiologies have been suggested for the formation of calcific depositions in the conjunctiva and cornea. ${ }^{1457}$ Besides disturbance of the calcium metabolism, calcification at the interpalpebral site has been shown to be related to the presence of an antecedent tissue degeneration which acts as a more calcifiable matrix and predisposes to calcium salt deposition. ${ }^{6}$
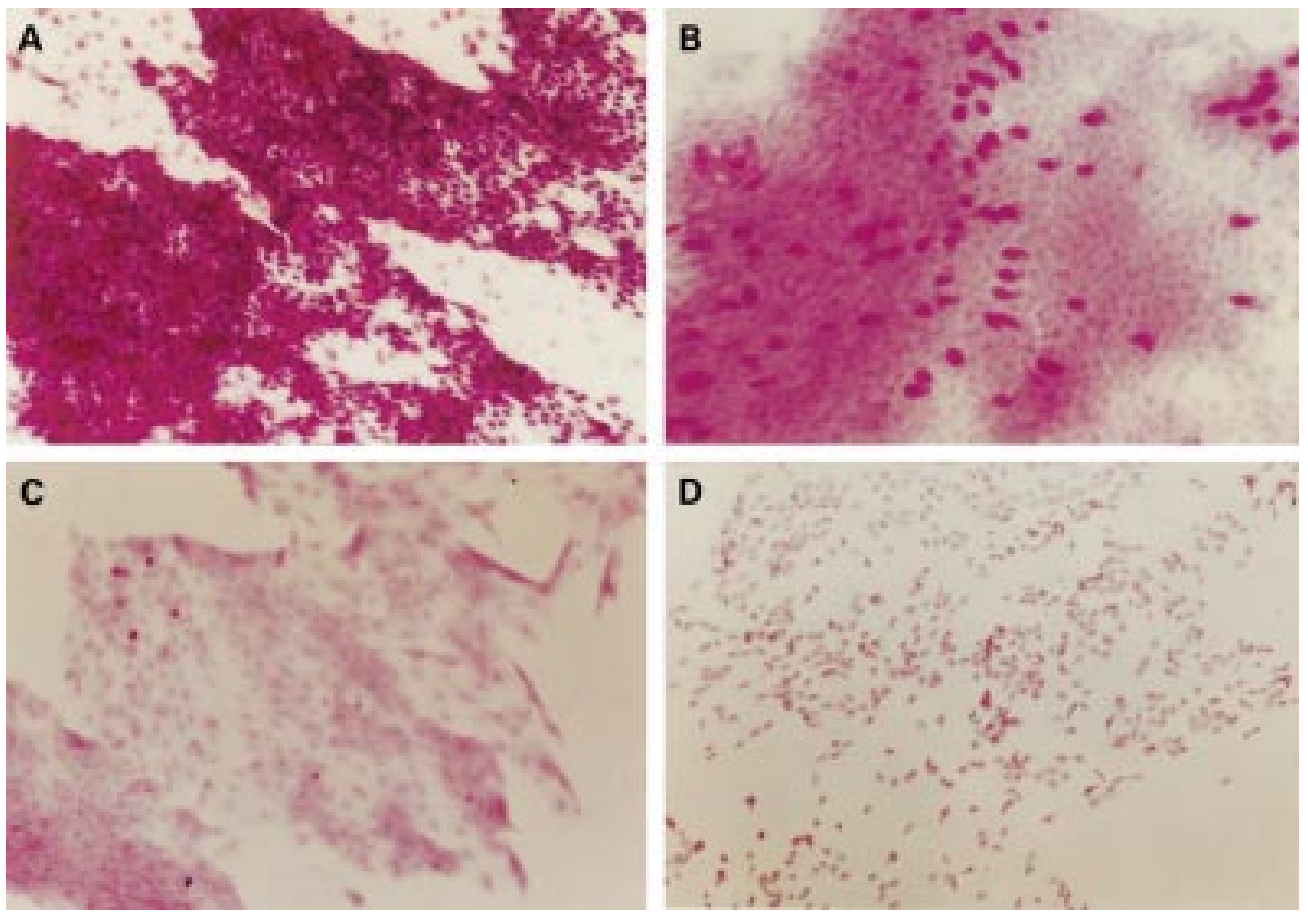

Figure 1 (A) Grade 0 = normal impression cytology specimen. (B) Grade $1=$ early loss of goblet cells. (C) Grade $2=$ marked decrease of goblet cells. (D) Grade $3=$ total loss of goblet cells, large epithelial cells. 
Conjunctival impression cytology, first described by Egbert et $a l^{8}$ is a safe, relatively simple, and painless method of obtaining specimens from the conjunctival surface. This technique allows the investigator to assess epithelial cell morphology, examine cytoplasmic and nuclear characteristics, and quantify the goblet cell population in the conjunctiva..$^{8-11} \mathrm{In}$ this study, we adapted this technique to study the conjunctival epithelial changes and correlate them with surface calcification in patients with CRF.

\section{Material and method}

Fifty patients, 21 males and 29 females aged 17-79 years (mean 45 years), receiving haemodialysis at Baskent University Hospital were recruited for the study. The patients' duration of CRF ranged from 5 to 392 months (mean 96 months), and their span of haemodialysis was 5-180 months (mean 60 months).

All patients underwent a complete ocular examination. Patients with a Schirmer value below $5 \mathrm{~mm}$ were not included in the study. Degenerative and calcific lesions of the conjunctiva and cornea were assessed by a slit lamp and were graded according to the criteria of Porter and Crombie. ${ }^{4}$ Impression cytology specimens were collected from the interpalpe-

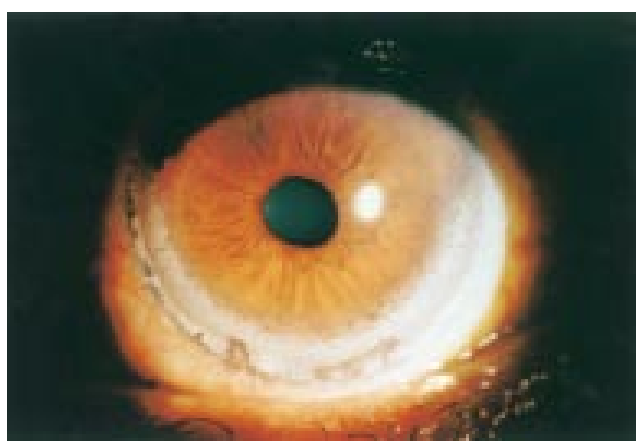

Figure 2. Corneo-conjunctival calcium deposits in chronic renal failure by slit lamp examination.

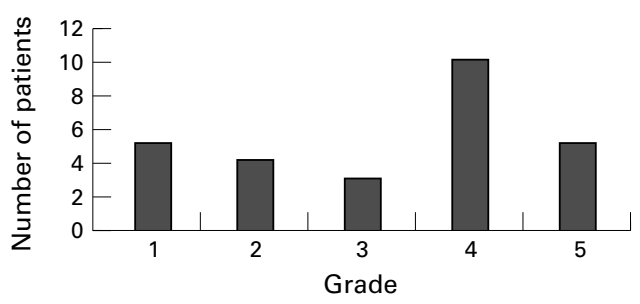

Figure 3 Results of grading of the corneo-conjunctival calcium deposits using Porter and Crombie's criteria in patients with chronic renal failure.

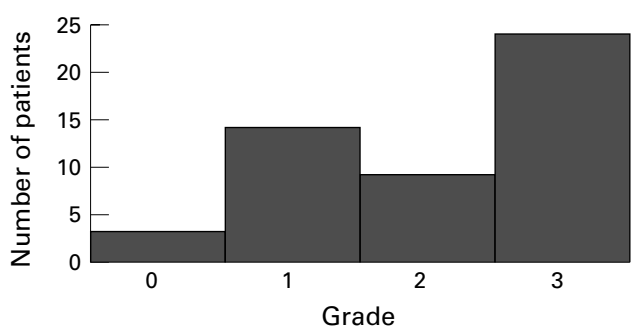

Figure 4 Results of grading using impression cytology results in patients with chronic renal failure bral temporal bulbar conjunctiva of one eye by the same physician (DD) using a cellulose acetate filter paper with pore size of $0.45 \mu \mathrm{m}$ (11106-47N Sartorius AG, Germany) according to the method described by Tseng. ${ }^{12}$

The samples were fixed in $95 \%$ ethanol, stained with periodic acid schiff (PAS), and examined in a Zeiss Axioplan light microscope, and graded by a masked observer (BD), using Nelson's classification. ${ }^{10}{ }^{13}$ In accordance with this method, presence and density of goblet cells, morphological changes in the nucleus, the nucleus-cytoplasma ratio, and metachromatic changes in the cytoplasm were considered for a scale from 0 to 3 (Fig 1A-D).

\section{STATISTICAL ANALYSIS}

The mean differences in age, duration of renal failure, and duration of haemodialysis in patients with impression cytology grade $0-1$ were compared with those with grade 2-3 using the Mann-Whitney U test. The impression grades of the control and the study group were compared using a $\chi^{2}$ test. The possible correlation between the distributions of the impression grades and the calcium deposit grades was investigated using a $\chi^{2}$ test.

\section{Results}

By slit lamp examination corneo-conjunctival calcium deposits of various grades were detected in 27 out of 50 CRF patients (Fig 2). In $17(63 \%)$ of these patients there were Grade 3-5 calcium deposits (Fig 3).

In this group, impression cytology revealed grade 0 changes in only three eyes. Fourteen eyes disclosed grade 1 while 33 eyes $(66 \%)$ had grades 2 and 3 alterations (Fig 4 ).

In the control group, there were grade $0-1$ changes in 17 subjects and grade 2-3 changes in 5 . There was a statistically significant difference between the study subjects and the controls with regard to distribution of the impression cytology grades $(\mathrm{p}=0.0007)$.

The relation between gradings for corneoconjunctival calcifications and impression cytology are summarised in Table 1. Grade 2-3 ocular surface change was evident in 15 of the 24 patients $(62 \%)$ who had no ocular calcium deposits. There was no correlation between the impression cytology grades and the calcium deposit grades $(p=0.62)$.

Mean age, duration of renal failure, and duration of haemodialysis did not differ significantly between patient groups with impression grades $0-1$ and grades $2-3(\mathrm{p}=0.585,0.97$, and 0.364 respectively).

\section{Discussion}

Interpalpebral conjunctival and corneal calcification is the most common form of metastatic calcification in patients with chronic renal failure. $^{3}$ These calcific deposits have been shown histologically to be calcium phosphate, and they are located within the basal epithelial cells as well as in the superficial subepithelial space. It is known that conjunctival degenerative changes comprise a notable part of the anterior segment findings in chronic renal failure. ${ }^{6}$ In 1966, Abrams ${ }^{14}$ drew attention to 
Table 1 Comparison of impression cytology grades with limboconjunctival calcium deposits

\begin{tabular}{llll}
\hline Calcium deposits grade & Number of patients & $\begin{array}{l}\text { Impression cytology } \\
\text { grade 0-1 }\end{array}$ & $\begin{array}{l}\text { Impression cytology } \\
\text { grade 2-3 }\end{array}$ \\
\hline 0 & 24 & 9 & 15 \\
$1-2$ & 9 & 2 & 7 \\
$3-5$ & 17 & 7 & 10 \\
\hline
\end{tabular}

the association of irritable red eyes and renal failure in a patient with limbal calcific deposits in the corneas. These deposits were extremely superficial and some had flaked off leaving small eroded areas which stained with fluorescein. Our clinical experience also shows that subepithelial calcium deposits frequently disrupt the overlying epithelium.

Goblet cell density reflects the overall health of the ocular surface and loss or a decrease in the density of goblet cells is an early sign of squamous metaplasia. ${ }^{12}{ }^{13}$ This abnormality in epithelial differentiation, referred to as squamous metaplasia, consists of a continuous spectrum in which the normal secretory conjunctival mucosa gradually develops into a non-secretory keratinised epithelium. As a result, the tear film becomes unstable secondary to a reduction in the mucin layer of the tear film. Squamous metaplasia can occur in a variety of dry eye conditions such as vitamin A deficiency and ocular cicatricial pemphigoid. ${ }^{15}$ Kidney and liver chronic failure interfere with vitamin A metabolism through their action on metabolic processes of synthesis and elimination. ${ }^{17}$ The levels of vitamin $\mathrm{A}$ and retinol binding protein levels have been investigated in patients with chronic renal disease undergoing (or not) dialysis. ${ }^{18}$ Hypervitaminosis $\mathrm{A}$ and an increase in retinol binding protein have usually been reported. ${ }^{19}$ In our patient group, the situation was the same and patients were being treated for high levels of vitamin A. Therefore, a squamous metaplasia due to vitamin A deficiency was not considered.

We used the impression biopsy technique to study the conjunctival epithelial features in CRF patients with and without calcium deposits; but changes in deeper layers of conjunctiva cannot be commented upon.

In our study, there were grade 3-5 calcium deposits in $63 \%$ of the CRF patients and the results of impression cytology showed that all cytological factors were significantly modified in $66 \%$ of the patients. These patients had grades 2 and 3 surface changes. In the control group, there were grade 2-3 changes in only five subjects. Fifteen patients with no calcium deposition disclosed grade 2-3 impression cytology changes. No statistical relation has been established between the ocular surface alterations and the severity of the calcium deposits. This finding does not support the hypothesis that the precipitation of calcium salts aggravates ocular surface modifications or vice versa.

Calcification at the interpalpebral site is believed to be related to the relatively alkaline environment at this site secondary to the loss of carbon dioxide from these exposed tissues, which leads to increased precipitation of calcium phosphate salts in the presence of an increased serum calcium phosphate product. $^{3}$ It has been shown that local factors, such as minor tissue injury of the limboconjunctival epithelium, referred to as "local challenger", are more likely to determine the degree of ocular calcification in dialysis patients than are systemic factors. ${ }^{20} \mathrm{~A} \mathrm{pH}$ elevation, or concentration by evaporation can lead to precipitation. ${ }^{21}$ In our study, the degree of ocular involvement did not correlate with the duration of haemodialysis or patient age.

The progression of altered conjunctiva is not correlated with the presence of calcium salts, which leads us to assume that ocular calcium precipitation, which occurs in the subepithelial area, has no direct relation with the process of squamous metaplasia. Therefore, these changes might be related with intrinsic factors such as uraemia and other metabolic imbalances. Increased understanding of the pathogenesis of this abnormal epithelial differentiation will enhance our ability to manage these ocular surface disorders more effectively.

1 Demco TA, Mc Cormick AQ, Richards JSF. Conjunctival and corneal changes in chronic renal failure. Can $\mathcal{f}$ aphthalmol 1974;9:208-13.

2 Ehlers N, Kruse Hansen F, Hansen HE, et al. Corneoconjunctival changes in uremia. Acta Ophthalmol 1972;50: 83-94.

3 Chestler R J, deVenecia G. Calcific eyelid margin lesions in chronic renal failure. Am f Ophthalmol 1989;107:556-7.

4 Porter R, Crombie A. Corneal and conjunctival calcification in chronic renal failure. $\mathrm{Br} \mathcal{F}$ Ophthalmol 1973;57:339-43.

5 Klaasen-Broekema N, van Bijsterveld OP. Limbal and corneal calcification in patients with chronic renal failure. Br f Ophthalmol 1993;77:569-71.

6 Klaasen-Broekema N, van Bijsterveld OP. The red eye of renal failure: a crystal induced inflammation?. $\mathrm{Br} F$ Ophthalmol 1992;76:578-81.

7 Easterbrook M, Mortimer CB. Ocular signs in chronic renal failure. Br F Ophthalmol 1970; 54:724-30.

8 Egbert PR, Lauber S, Maurice MD. A simple conjunctival biopsy. Am f Ophthalmol 1977;84:798-801.

9 Paridaens ADA, McCartney ACE, Curling OM, et al. Impression cytology of conjunctival melanosis and Impression cytology of conjunctival melano
melanoma. Br f Ophthalmol 1992;76:198-201.

10 Nelson JD, Havener VR, Cameron JD. Cellulose acetate impressions of the ocular surface: dry eye states. Arch Oph-
im thalmol 1983;101:1869-72.

11 Kinoshita S, Kiorpes TC, Friend J, et al. Goblet cell density in ocular surface disease. Arch Ophthalmol 1983;101:12847.

12 Tseng SCG. Staging of conjunctival squamous metaplasia by impression cytology. Ophthalmology 1985;92:728-33.

13 Tseng SCG, Hirst LW, Maumenee AE, et al. Possible mechanisms for the loss of goblet cells in mucin-deficient disorders. Ophthalmology 1984;91:545-52.

14 Abrams JD. Corneal and other ocular findings in patients on intermittent dialysis for renal failure. Proc Roy Soc Med 1966;59:533-4.

15 Nelson JD, Wright CJ. Conjunctival goblet cell densities in ocular surface disease. Arch Ophthalmol 1984;102:104951 .

16 Natadisastra G, Wittpenn JR, West KP Jr, et al. Impression cytology for detection of vitamin A deficiency. Arch cytology for detection of vitar

17 Adoncecchi L, Marrocco W, Suraci C, et al. Effect of renal and liver failure on blood levels of vitamin A, its precursor (beta-carotene) and its carrier proteins. Boll Soc Ital Biol Sper 1984;60:881-6.

18 Vannucchi MT, Vannucchi H, Humphreys M. Serum levels of vitamin A and retinol binding protein in chronic renal ailure patients treated by continous ambulatorial peritoneal dialysis. Int $\mathcal{F}$ Vitam Nutr Res 1992;62:107-12.

19 Stein G, Schone S, Geinitz D, et al. No tissue level abnormality of vitamin A concentration despite elevated serum vitamin A of uremic patients. Clin Nephrol 1986;25: $87-93$.

20 Klaassen-Broekema N, van Bijsterveld OP. A local challenger of ocular calciphylaxis in patients with chronic renal failure: a hypothesis. Graefes Arch Clin Exp Ophthalmol 1995;83:717-20.

21 Lavid FJ, Herreras JM, Calonge M, et al. Calcerous corneal degeneration: report of two cases. Cornea 1995;14:97-102. 